\title{
As Elegias de Buckow, de Bertolt Brecht: tempos sombrios depois da guerra
}

\author{
[Bertolt Brecht's Buckow Elegien: dark times after the war] \\ http://dx.doi.org/10.11606/1982-88372444351
}

\section{Tercio Redondo ${ }^{1}$}

\begin{abstract}
This article deals with the Buckow Elegies [Buckower Elegien], which Brecht began to write in mid-1953. Eight of these elegies have been selected for analysis and commentary. The investigation is focused on the author's criticism of the social and political situation of former East Germany at that time, a moment when fascist elements were still in place in a society whose main goal was supposed to be the attainment of socialism. In terms of form, this article seeks to demonstrate, also by tackling poems from the period of the war, the way in which Brecht, in these elegies, changes the perspective on regret by considering historically configured needs.
\end{abstract}

Keywords: Bertolt Brecht; Buckow Elegies; Criticism of fascism.

Resumo: O presente artigo versa sobre as Elegias de Buckow [Buckower Elegien], produzidas por Brecht a partir de meados de 1953. Para análise e comentário foram selecionados 8 poemas da obra. Nestes procura-se verificar a crítica do autor à situação político-social da Alemanha Oriental nessa época, num quadro de reapresentação de elementos fascistas numa sociedade a que se atribuía a construção do socialismo. No plano formal, procura-se salientar - apelando-se também a poemas anteriores, escritos durante a guerra - a maneira com que, nas elegias, Brecht altera a perspectiva do lamento para atender a necessidades historicamente configuradas.

Palavras-chave: Bertolt Brecht; Elegias de Buckow; Crítica do fascismo.

Em carta ao amigo e editor Peter Suhrkamp, escrita em fins de novembro de 1953, Brecht menciona um conjunto de poemas por ele chamados de "Buckowlische Elegien [Elegias Buckólicas]", termo derivado de Buckow, nome de uma pequena vila localizada cerca de $50 \mathrm{~km}$ a leste de Berlim. Nos Journale [Diários de trabalho], em registro de 14 de fevereiro de 1952, ele relata o início da história:

\footnotetext{
${ }^{1}$ Universidade de São Paulo, Faculdade de Filosofia, Letras e Ciências Humanas, Departamento de Letras Orientais, Av. Prof. Luciano Gualberto, 403, 05508-900, São Paulo/SP, Brasil. Email: tercioredondo@terra.com.br. ORCID: 0000-0003-2722-3733

Este artigo integra um estudo mais amplo sobre a crítica de Brecht ao fascismo que contou com bolsa da Fapesp para um estágio de pesquisa na Universidade de Oxford no primeiro semestre de 2018.
}

\section{(cc) BY-NC}

Pandaemonium, São Paulo, v. 24, n. 44, set.-dez. 2021, p. 351-373 
Na Suíça Brandenburguesa ${ }^{2}$ Helli $^{3}$ e eu passamos em revista algumas casas de campo. Num belo terreno à beira do lago Schermützelsee, achamos uma casinha velha, mas digna, rodeada por altas árvores e acompanhada de outra, a 50 metros de distância, mais espaçosa, mas igualmente simples. Algo assim seria acessível para nosso bolso, quanto aos custos de manutenção inclusive. Na casa maior, poderíamos receber alguns hóspedes (BRECHT 1995: 330). ${ }^{4}$

A propriedade foi arrendada em seguida pelo casal, e em 15 de julho Brecht anotava: "A casa e seu entorno estão suficientemente em ordem, de modo que posso retornar à leitura de Horácio" (BRECHT 1995: 330). A partir de então a propriedade lhe ofereceria um refúgio seguro em relação à azáfama de Berlim e uma paisagem em que ele iria flagrar uma parte dos elementos de tensão de que se originam as elegias. Seis delas foram publicadas ainda em 1953 na revista Sinn und Form, com título alheio ao trocadilho feito na carta a Suhrkamp. A pequena mostra foi chamada simplesmente de Gedichte [poemas]. Um grupo maior, de 23 elegias, foi publicado em 1964, oito anos após a morte do autor, e a grande antologia inglesa de Tom Kuhn e David Constantine, de 2019, acrescentou-lhe mais quatro a partir de uma lista presente numa nota de Käthe Reichel (BRECHT 2019: 1012), desde 1950 atriz do Berliner Ensemble ${ }^{5}$ e última relação amorosa de Brecht.

Cabe desde logo ressaltar que o termo elegia é utilizado por Brecht de maneira não ortodoxa, numa relação bastante livre com um legado que remonta à antiguidade clássica. Como salienta Ullrich Kitstein,

As dificuldades de interpretação começam já pela caracterização do gênero, pois ambas as definições tradicionais mais importantes do conceito de elegia, que coexistem desde a Antiguidade, não podem ser aqui empregadas. Habitualmente, a elegia é definida ou como poesia que expressa luto e pesar em torno de uma perda sofrida ou, de modo puramente formal, como obra lírica elaborada em dísticos [...]. A partir dessas observações dificilmente obteremos uma justificativa para a escolha que Brecht fez para essa denominação de gênero. (KITSTEIN 2012: 314-315)

Franz Norbert Mennemeier acrescenta ao reparo a advertência de que quem “quiser buscar nas Elegias de Buckow uma poética do atemporal, não estará lendo os poemas corretamente; terá apressadamente abstraído da situação histórica em que elas surgiram e foram cunhadas.” (MENNEMEIER 1982: 208). Da mesma maneira, Klaus Schuhmann observa que nos poemas do pequeno ciclo a forma elegíaca não é

\footnotetext{
${ }^{2}$ Suiça Brandenburguesa [Märkische Schweiz]: região do Estado de Brandenburgo, na Alemanha, onde se localiza a vila de Buckow.

${ }^{3}$ Helli: Helene Weigel.

${ }^{4}$ Salvo advertência em contrário, as traduções dos textos citados neste artigo, dos poemas inclusive, são de minha responsabilidade.

${ }^{5}$ O teatro fundado por Brecht e Weigel em Berlim Oriental em 1949.
} 
REDONDO, T. - As Elegias de Buckow, de Bertolt Brecht

imediatamente identificável, inclusive pelo fato de não se tratar de uma poesia de lamentação em sentido estrito. Nas elegias de Brecht ele observa a persistência de um modo singular de expressão do sentimento pesaroso,

não como lamento sobre uma condição humana que se perdeu e sobre um ideal inatingível, mas como autoquestionamento crítico, com o propósito de medir e tomar consciência da discrepância entre o que se pode alcançar e o que foi alcançado (SCHUHMANN 1977: 109).

De fato, "aqui e ali notam-se alusões a acontecimentos do presente." (KITTSTEIN 2012: 317). A lápide tem, portanto, novo endereço. Deixa o túmulo e passa a sinalizar as agruras dos vivos, conservando, contudo, um elemento que é peculiar a boa parte da produção lírica brechtiana: o esforço de concisão do verso. Em sua maioria, os poemas são bastante breves; apenas cinco contam mais de 10 versos e 19 têm um máximo de sete.

Sem embargo do que se verifica nas elegias do ciclo de Buckow, Brecht chegou a escrever poemas que, à primeira vista, atendem ao quesito de "lamentação em sentido mais estrito" a que se refere Klaus Schuhmann. Ele o fez, por exemplo, para homenagear Walter Benjamin, que se suicidara juntamente com a mulher, quando procurava escapar da França ocupada, em setembro de 1940. Brecht soube da morte de Benjamin apenas em meados do ano seguinte, depois de ter chegado aos Estados Unidos. Nesse caso, porém, à elegia justapõe-se um comentário, ocorrendo assim um movimento de expansão da forma, em procedimento que, por fim, acarreta sua implosão (por excesso) e consequente reconfiguração.

\section{SOBRE A MORTE DO FUGITIVO W.B. ${ }^{6}$}

Ouvi dizer que ergueste a mão contra ti mesmo

Antecipando-te ao carrasco.

Há oito anos banido, posto a observar a ascensão do inimigo

Levado por fim a uma intransponível fronteira

Transpuseste, diz-se, uma transponível.

Impérios sucumbem. Chefes de gangues

Circulam por aí feito homens de Estado. Sob as armaduras

Os povos já não podem ser vistos.

Assim, o futuro jaz nas trevas, e são débeis

As forças do bem. Viste tudo isso

Ao destruíres o corpo torturável.

\footnotetext{
${ }^{6}$ „ZUM FREITOD DES FLÜCHTLINGS W.B.// Ich höre, daß du die Hand gegen dich erhoben hast/ Dem Schlächter zuvorkommend./ Acht Jahre verbannt, den Aufstieg des Feindes beobachtend/ Zuletzt an eine unüberschreitbare Grenze getrieben/ Hast du, heißt es, eine überschreitbare überschritten.// Reiche stürtzen. Die Bandenführer/ Schreiten daher wie Staatsmänner. Die Völker/ Sieht man nicht mehr unter den Rüstungen.// So liegt die Zukunft in Finsternis und die guten Kräfte/ Sind schwach. All das sahst du/ Als du den quälbaren Leib zerstörst." (BRECHT 1993c: 48).
} 
Vista isoladamente a primeira estrofe do poema constitui uma unidade autônoma, apresentando conteúdo e forma que atendem aos requisitos mínimos do que se poderia chamar de elegia moderna, no sentido daquela poesia de luto referida por Kitstein. Notese, porém, que as estrofes seguintes lhe adicionam informação estranha ao ato perpetrado pela figura que é pranteada. Nelas a morte passa a se vincular inextrincavelmente à circunstância da ascensão nazifascista, e os dois últimos versos do poema podem ser mais bem compreendidos à luz de uma anotação de Brecht nos Diários de trabalho, em 9 de agosto de 1941:

Walter Benjamin envenenou-se numa pequena localidade espanhola na fronteira. A gendarmaria havia detido o pequeno grupo que ele integrava. Na manhã seguinte, quando seus acompanhantes foram avisá-lo de que estavam autorizados a seguir viagem, acharam-no morto. Leio agora o último trabalho que ele enviou ao Instituto de Pesquisa Social. Günther Stern ${ }^{7}$ passou-me o texto com a observação de que é obscuro e confuso [...]. O pequeno ensaio trata da investigação da história [...] Benjamin volta-se contra a representação da história como uma evolução [Ablauf], do progresso como um vigoroso empreendimento de cabeças descansadas, do trabalho como fonte da moralidade, dos trabalhadores como protegidos da técnica etc. Ele zomba da frequente afirmação de que deveríamos nos surpreender com o fato de que algo como o fascismo pudesse ocorrer "ainda neste século" ${ }^{8}$ (como se não fosse o fruto de todos os séculos). Em suma, o pequeno trabalho é claro e elucidativo (a despeito de todas as metáforas e judaísmos), e ficamos estarrecidos ao notarmos o quão pequeno é o número daqueles que estão dispostos a enfrentar a questão, nem que o seja de maneira equivocada (BRECHT 1995: 12).

O texto recebido de Stern é o das teses benjaminianas da Filosofia da história. No poema Brecht evoca o "pequeno ensaio" ou, por outra, reproduz de maneira concentrada o cenário contemplado por Benjamin em sua fracassada tentativa de fuga: o futuro sombrio, desde havia muito anunciado, os trabalhadores imersos no tempo homogêneo e vazio da modernidade capitalista, o fascismo triunfante como a representação mais acabada de progresso.

Para dialogar com Benjamin, Brecht procede a uma epicização da forma, ciente de que a redução do poema a sua estrofe inicial implicaria inevitavelmente um gesto de banalização da memória. À primeira estrofe não falta sequer o fecho lapidar: "Levado por fim a uma intransponível fronteira/ Transpuseste, diz-se, uma transponível.” Mas os versos submetem-se à mesma sorte de demonstração descrita por Brecht na Cena de rua, o modelo "primitivo" de que deriva seu teatro épico, ou dialético:

A testemunha ocular de um acidente de trânsito demonstra a um grupo de pessoas como o sinistro ocorreu. Essas pessoas podem não ter presenciado o evento ou talvez não compartilhem a opinião do demonstrador, podem "tê-lo visto de outro modo" - a questão

\footnotetext{
${ }^{7}$ Günther Stern: nome civil de Günther Anders.

${ }^{8}$ Ele zomba $[\ldots]$ "ainda neste século”: Brecht está citando quase literalmente o amigo morto. Benjamin na VIII Tese da Filosofia da História: "O espanto em constatar que os acontecimentos que vivemos 'ainda' sejam possíveis no século XX não é nenhum espanto filosófico.” (apud LöWY 2005: 83).
}

Pandaemonium, São Paulo, v. 24, n. 44, set.-dez. 2021, p. 351-373 
principal consiste em que o demonstrador expõe o comportamento do motorista ou o do atropelado ou o de ambos de maneira tal que os circunstantes possam formar um juízo sobre o acidente (BRECHT 1993d: 371).

Nessa perspectiva a demonstração do evento tem propósito definido: promover a representação do acidente de tal modo que leve os espectadores à formação de uma opinião sobre o ocorrido, baseada em atitude distanciada e crítica. No poema a primeira estrofe expressa fundamentalmente o momento extremo que conduz ao desenlace fatal, fornecendo decerto um mínimo de informação acerca da circunstância pessoal do perseguido: "Há oito anos banido, posto a observar a ascensão do inimigo". Contudo, a voz lírica não olvida o fato de que a atitude da vítima excede a condição de mera contemplação da catástrofe. Mais que passivo observador da ascensão do inimigo, Benjamin havia sido um investigador original e arguto da crise que levara ao esfarelamento da ordem mundial que emergira dos escombros da Primeira Guerra. Seus olhos viram e analisaram a perda de substância do Estado liberal e a ascensão do gangsterismo fascista, a supressão do projeto revolucionário de emancipação popular, seguida pela Gleichschaltung ${ }^{9}$ do Terceiro Reich, aludida nos dois últimos versos da segunda estrofe: “[...] Sob as armaduras/ Os povos já não podem ser vistos.” Benjamin vira a distópica engrenagem técnica de Ernst Jünger posta a se mover na produção do trabalhador-soldado ${ }^{10}$, cujos traços humanos não mais podiam ser reconhecidos.

As elegias de Brecht mantêm o elemento de circunspecção e a atitude solene diante do infortúnio, mas, ao mesmo tempo, justamente para se atualizar e viabilizar, acolhem matéria em princípio alheia à manifestação do lamento. Mais que chorar o amigo morto, Brecht rende homenagem a seu pensamento militante, observado nas condições históricas em que se produziu. A morte de Walter Benjamin não havia simplesmente selado uma biografia exemplar, ela dava testemunho de um processo em pleno curso: em 22 de junho de 1941 a Wehrmacht invadira a União Soviética, e naquele momento era

\footnotetext{
${ }^{9}$ Gleichschaltung: processo de ampla reorganização social promovido pelo nazismo, fundamentado na convergência de toda a energia e vontade do povo para os fins estabelecidos pelo Estado totalitário. Todo o aparato institucional, da igreja aos sindicatos, passando pela escola e chegando à intimidade doméstica, foi alvo de medidas que visavam a uma uniformização do pensamento e das atitudes da população alemã. ${ }^{10}$ Em Der Arbeiter, longo ensaio publicado em 1932, Jünger trata do que seria o surgimento de um tipo social novo, o trabalhador numa nova configuração [Gestalt] subordinada à técnica e apta para o empreendimento bélico total, com o mundo civil e o militar implicados numa atividade sincrônica. Ao comentar o desarmamento que foi imposto à Alemanha após a Primeira Guerra, Jünger apontou para a impossibilidade de sua plena execução e anteviu a transformação social que seria levada a cabo pelo nazismo: "Pode-se eliminar o exército, mas não o fato de que povos inteiros serão tomados pela vontade da formação de organizações de tipo militar - e talvez tomados de modo tão mais garantido quanto mais claramente for definida a especial preparação para a guerra. [...] A mobilização por meio do serviço militar obrigatório será, portanto, substituída pela mobilização total, ou do trabalho.” (JÜNGER 2014: 303-304).
}

Pandaemonium, São Paulo, v. 24, n. 44, set.-dez. 2021, p. 351-373 
REDONDO, T. - As Elegias de Buckow, de Bertolt Brecht

real a ameaça de uma vitória nazista sobre todo o continente europeu. Daí a ruptura com o ponto de vista de um lamento do que ficou para trás. Independentemente do que se pudesse dizer de Walter Benjamin, sua morte era índice da atualidade do ascenso nazifascista, narrado de maneira concentrada na segunda estrofe do poema: "Impérios sucumbem. Chefes de gangues/ Circulam por aí feito homens de Estado. Sob as armaduras/ Os povos já não podem ser vistos." Observada a cisão entre o elemento "elegíaco" e aquilo que se segue, é possível dizer que a primeira estrofe do poema corresponde à forma esperada, ao passo que as duas estrofes seguintes constituem um aposto, à maneira de um comentário. A forma original permanece útil e válida, mas deixa de ser autossuficiente; não se sustenta sem o apêndice que circunstancia o evento trágico, sendo a narrativa adicional dos eventos a chave para a compreensão de que a morte não está de todo morrida, que ela continua a ser cotidianamente reiterada, restando truncado o processamento do luto e impedido seu desfecho de serena rememoração.

Nas Elegias de Buckow, como se verá adiante, subverte-se igualmente a perspectiva temporal da manifestação de pesar, que é deslocada para o presente histórico e transposta do plano das afinidades pessoais para o terreno da crítica politicamente motivada, observando-se, contudo, que o processo de expansão do conteúdo pela via da posposição apendicular cede o passo a uma transformação interna, nuclear, num processo que lhe renderá por fim um resultado de grande concisão.

Depois de seis anos de exílio nos Estados Unidos, o retorno de Brecht à Europa não foi precedido por planejamento que houvesse contemplado um novo endereço, num país que o acolhesse de bom grado, onde ele e Helene Weigel pudessem finalmente retomar o trabalho prático no teatro, virtualmente suspenso desde a fuga da Alemanha em 1933. Em 30 de outubro de 1947 Brecht fora interrogado pelo Comitê sobre Atividades Antiamericanas da Câmara dos Representantes, em Washington. Era o início da era macartista, e seus inquisidores questionavam os possíveis vínculos que ele pudesse ter com um partido comunista, bem como seu trabalho na indústria cinematográfica em Hollywood. Gato escaldado, Brecht deixou o país no dia seguinte, num voo para Paris. A Europa tampouco o recebeu de braços abertos. Os nazistas haviam-lhe confiscado a cidadania alemã, e a condição apátrida não se alterara desde então. No teatro sua atividade dependia de amigos que o empregassem, sem que seu nome, por precaução, figurasse nos créditos de produção; os fascistas da nova restauração europeia, na democrática Suíça inclusive, estavam a postos para denunciá-lo e impedi-lo de exercer suas atividades 
REDONDO, T. - As Elegias de Buckow, de Bertolt Brecht

livremente. Por fim, a Áustria, país natal de Helene Weigel, concedeu-lhe a cidadania, e ele recebeu um convite para se estabelecer em Berlim Oriental. Lá, dificuldades análogas às enfrentadas nos tempos do exílio rapidamente se apresentaram. Sua arte e sua postura de independência política granjearam-lhe desde o início a antipatia e a má vontade dos que se haviam encastelado no aparato cultural do Estado. Não foram poucos os percalços enfrentados em sua tentativa de pôr em prática aquilo que aprendera antes e durante a guerra, no longo caminho de amadurecimento de suas ideias em torno do teatro épico. Em junho de 1951, o Comitê Central do Partido Socialista Unido da Alemanha (SED) emitiu um parecer sobre o recém-criado Berliner Ensemble:

Predomina a maneira brechtiana de fazer teatro. Essa maneira consiste essencialmente em negligenciar a cuidadosa configuração realista da cenografia, exibir invariavelmente tendências unilaterais de culto ao proletariado e em "simplificar" as performances dos atores até o limite da indigência. [...] A camarada Rodenberg, colaboradora da sessão [de artes cênicas da Academia de Artes] acrescentou: "Brecht é bom, mas não deve fazer escola." (apud KNOPF 2012: 494-95).

Dois anos depois, enquanto Brecht e Weigel pressionavam as autoridades culturais pelo cumprimento da promessa de concessão de um teatro para sediar sua companhia, Wilhelm Girnus, alto funcionário do partido na área de educação e cultura comunicou-se com Walter Ulbricht, na época em plena ascensão política e prestes a assumir a liderança isolada do partido e do governo. Girnus:

[...] na tarde do domingo, 25 de julho de 1953, tive uma longa conversa com Bertolt Brecht. [...] Independentemente da opinião que tenhamos sobre suas singulares teorias e levando em consideração uma série de questões, especialmente a repercussão internacional, parece-me insustentável que se lhe continue negando a concessão de um teatro. Ademais, feita essa concessão, conto com um efeito pedagógico, pois, com seu teatro, ele terá de provar que é capaz de conquistar o público, sobretudo os trabalhadores. Com os meios que apresentou até agora, não vai conseguir. Portanto, não devemos entregar-lhe uma coisa menor, mas um verdadeiro teatro. Assim, ele não poderá escusar seu primitivismo e puritanismo sob a alegação da carência de recursos técnicos. (apud KNOPF 2012: 503-504).

Por volta de 17 de junho, cinco semanas antes de Girnus redigir seu relato, um levante popular eclodira em Berlim e noutras cidades da Alemanha Oriental. Greves e protestos demandavam melhores salários e melhores condições trabalho, além de uma pauta de reivindicações políticas que incluíam a deposição do governo e eleições livres. A situação expunha claramente a insatisfação popular com os rumos econômicos e sociais do país, decididos de modo centralizado e cada vez mais apartado da realidade social. O movimento foi brutalmente reprimido sob o tacão das forças de ocupação soviéticas, restando um saldo de dezenas de mortos e numerosos detidos, dentre os quais alguns 
REDONDO, T. - As Elegias de Buckow, de Bertolt Brecht

seriam sentenciados com a pena capital. As Elegias de Buckow foram escritas sob o impacto imediato desses acontecimentos e traduzem a amarga reação de Brecht em face do adiantado processo de stalinização do regime e das limitações impostas à intervenção política da arte, além de revelarem um sombrio sentimento pessoal de culpa e impotência.

Dentre as elegias não publicadas à época, encontra-se Die Lösung [A solução] ${ }^{11}$ :

Após o levante de 17 de junho

O secretário da União dos Escritores fez

Distribuir panfletos na Alameda Stalin

Nos quais se lia que o povo

Havia traído a confiança do governo

E só poderia reconquistá-la

À custa de redobrado esforço. Não seria

Mais simples o governo

Dissolver o povo e

Eleger outro?

Como informa a edição alemã,

O poema baseia-se num evento real. Kuba (Kurt Barthel), em 1953 ocupando o cargo de secretário da Associação dos Escritores da RDA [República Democrática Alemã] e membro do Comitê Central do SED, ataca abertamente, no jornal Neues Deutschland, em 20 de junho de 1953, os trabalhadores que haviam protestado, e diz ameaçadoramente que, doravante, teriam de trabalhar ainda mais, "até que essa vergonha [fosse] esquecida". A reprimenda de Kuba desencadeou acerbas discussões na imprensa da RDA e ocasionou sua destituição do secretariado (BRECHT 1993a: 448).

De Berlim Ocidental Suhrkamp escreveu a Brecht pedindo sua opinião sobre os eventos. A resposta chegou-lhe numa longa carta, datada de $1^{\circ}$ de julho, em que o escritor avalia a natureza política dos protestos e comenta sua própria posição em relação a eles e os ataques que recebeu da imprensa da República Federal:

Você pergunta sobre minha posição acerca dos acontecimentos de 16 e 17 de junho. Tratou-se acaso de um levante popular, de uma tentativa de se "obter liberdade", como afirma quase toda a imprensa da Alemanha Ocidental? Acaso assumi uma atitude indiferente ou mesmo beligerante diante de um levante popular? Em 17 de junho, escrevi uma carta ao Partido Socialista Unido da Alemanha, cuja frase final foi publicada. Posteime acaso contra a liberdade quando, nessa carta, declarei-me pronto, à minha maneira (na forma artística), a contribuir para o debate absolutamente necessário entre trabalhadores e governo? Por três décadas, busquei defender a causa dos trabalhadores em meus escritos. Na noite de 16 e na manhã de 17 de junho, porém, vi as impressionantes demonstrações dos trabalhadores transformarem-se em algo muito distinto de uma tentativa de se obter liberdade. Eles tinham o direito de estar furiosos. As infelizes e imprudentes medidas governamentais destinadas à célere construção de uma indústria pesada no território da RDA fizeram com que, ao mesmo tempo, camponeses, artesãos, comerciantes, trabalhadores e intelectuais se voltassem contra o governo. [...] Já nas

11 „DIE LÖSUNG// Nach dem Aufstand des 17. Juni/ Ließ der Sekretär des Schriftstellerverbands/ In der Stalinallee Flugblätter verteilen/ Auf denen zu lesen war, daß das Volk/ Das Vertrauen der Regierung verscherzt habe/ Und es nur durch verdoppelte Arbeit/ Zurückerobern könne. Wäre es da/ Nicht doch einfacher, die Regierung/ Löste das Volk auf und/ Wählte ein anderes?““(BRECHT 1993a: 310).

Pandaemonium, São Paulo, v. 24, n. 44, set.-dez. 2021, p. 351-373 
primeiras horas da manhã de 17 de junho, a rua misturava grotescamente os semblantes de trabalhadores e trabalhadoras com toda sorte de jovens desclassificados [...], bem como com as nítidas e brutais figuras dos tempos do nazismo, figuras locais que há anos não mais se apresentavam em grandes grupos e que, todavia, sempre estiveram aqui. As palavras de ordem mudaram rapidamente. De "Abaixo o governo!" passou-se a "Enforquem-no!" [...]. Por volta do meio-dia, o fogo começou a desempenhar seu velho papel. Da Alameda Unter den Linden podia-se ver a nuvem de fumaça vinda do prédio da Columbushaus, em Potsdamer Platz, junto à divisa entre os setores, tal como a nuvem de fumaça do prédio do Reichstag num desafortunado dia do passado. Hoje, como então, não foram os trabalhadores que acenderam o fogo: ele não é a arma dos que constroem. [...] Em alguns lugares houve assaltos a judeus, não muitos, já que não há muitos judeus. (BRECHT 1998: 182-84).

O governo da RDA dera imediata publicidade à declaração de lealdade do escritor proeminente, ocultando, porém, seu apelo para que os trabalhadores fossem ouvidos numa discussão democrática sobre os rumos do país. As grandes manifestações daquele mês de junho, a repressão violenta e a recusa do regime em dialogar passavam a indicar uma reatualização dos "tempos sombrios" que Brecht havia deparado nos tempos do exílio. Em A solução o processo de ruptura entre os planos governamentais para a economia e os anseios e necessidades das massas trabalhadoras adquire contornos surpreendentes. O grau extremo de alienação a que haviam chegado o partido e o governo conduz o poema a um fecho insólito: não é mais o governo que trai a confiança do povo, é o representado que perde paradoxalmente a confiança do representante, de modo que a voz lírica é forçada a formular uma pergunta para a qual não há resposta possível. Raras vezes o agudo momento de apartação entre governantes e governados fora registrado com tamanha precisão. Aqui a lírica se apresenta como forma avançada e privilegiada de expressão da viravolta política: "não seria mais simples o governo dissolver o povo e eleger outro?"

Na carta a Suhrkamp, sobressai um dado que reaparece em mais de uma elegia: a persistência do elemento nazista na RDA. Na Alemanha Ocidental do pós-guerra, os nazistas foram relativamente pouco incomodados, e muitos deles logo se aclimataram aos novos tempos. Não lhes faltaram oportunidades de inserção social e profissional, tendo ocupado cargos de destaque até mesmo no aparato judicial, e o governo Adenauer contou com a estreita colaboração de notórios “ex"-hitleristas. No lado oriental, entretanto, a tolerância havia sido desde o início muito menor, e a rediviva forma nazi de manifestação pública não passou despercebida a Brecht, velho estudioso de sua teatralidade ${ }^{12}$. Não obstante, não se tratava apenas de nazistas dispostos a ressurgir na forma de agitadores

\footnotetext{
${ }^{12}$ Cf. Über die Theatralik des Faschismus (BRECHT 1993d: 561-69).
} 
REDONDO, T. - As Elegias de Buckow, de Bertolt Brecht

políticos e incendiários. Também não se tratava de lidar com meros resquícios de um passado remoto. A perseverança de traços significativos da mentalidade fascista era perceptível, por exemplo, na disciplina imposta a uma nova geração de educandos na socialista RDA:

\author{
HÁBITOS, AINDA ${ }^{13}$ \\ Os pratos são dispostos rudemente \\ E a sopa se derrama sobre a mesa. \\ Com voz estridente \\ Ressoa o comando: comer! \\ A águia prussiana \\ Enfia goela abaixo \\ A comida de seus rebentos.
}

O poema descreve quatro eventos simultâneos, que podem ser sumarizados como segue: "pratos são dispostos", "a sopa se derrama", "ressoa o comando" e "enfia goela abaixo a comida". Os três primeiros configuram uma cena tirada do cotidiano de uma instituição de ensino, não importando aqui se os comensais são alunos de um orfanato ou de uma escola ou ainda cadetes de uma academia do exército ou da polícia. Na cena sobressai a ordem unida, a voz de comando, a sincronização obrigatória do simples ato de comer em grupo. Fecha a descrição o quarto evento, realizado sob os augúrios da águia prussiana, a figura totêmica a que se subordina o clã faminto.

Os atos praticados na primeira estrofe do poema são executados por sujeitos anônimos. Não se nomeiam aqueles que dispõem os pratos rudemente, nem tampouco é nomeado aquele que dita a ordem de comer. É apenas na segunda estrofe que um sujeito deixa de se ocultar e se revela como agente da ação, assumindo o protagonismo da cena. Simbolicamente, ele contextualiza o despejo dos pratos sobre a mesa e imprime significado histórico à ordem dada pela voz de comando e ao ato de obediência correspondente. $\mathrm{Na}$ Alemanha pretensamente socialista a imagem da águia prussiana sinalizava uma forma de vida que se organizava hierárquica e disciplinarmente, de cima para baixo, num ritual de condicionamento social cuja origem era identificável e cujas consequências eram previsivelmente funestas. Brecht considerava a disciplina ou, melhor dizendo, a autodisciplina, um instrumento imprescindível para o trabalho, o artístico sobretudo, mas destacava-a da obediência com que ela frequentemente se confundia,

\footnotetext{
13 „GEWOHNHEITEN, NOCH IMMER// Die Teller werden hart hingestellt/ Daß die Suppe überschwappt./ Mit schriller Stimme/ Ertönt das Kommando: Zum Essen!// Der preußische Adler/ Den Jungen hackt er/ Das Futter in die Mäulchen.“(BRECHT 1993a: 307).
}

Pandaemonium, São Paulo, v. 24, n. 44, set.-dez. 2021, p. 351-373 
REDONDO, T. - As Elegias de Buckow, de Bertolt Brecht

especialmente no meio militar. Em Fünf Schwierigkeiten beim Schreiben der Wahrheit [Cinco dificuldades ao escrever a verdade], texto de 1934, ele havia salientado a necessidade de o escritor antifascista substituir certas palavras por outras para distinguilas das frequentes distorções que a propaganda nazista infligia ao léxico alemão. Assim, ele sugeria que onde reinasse a opressão, "deveríamos trocar disciplina por obediência, pois a disciplina é possível também sem que haja dominadores [...].” (BRECHT 1993d: 82).

Imagem semelhante à da ninhada famélica, umbilicalmente dependente da figura aquilina, é oferecida noutra elegia, Der Himmel dieses Sommers [O céu deste verão] ${ }^{14}$ :

Um bombardeiro sobrevoa o lago em grande altitude.

Nos barcos a remo

Crianças, mulheres e um ancião erguem os olhos. De longe

Parecem estorninhos de bicos abertos

Em direção ao alimento.

Aqui, a aparição do bico aberto em busca de comida identifica-se não mais com um coletivo restrito de infantes ou adolescentes enclausurados numa instituição educacional, mas com um grupo consideravelmente mais diverso. Infância, maturidade e velhice estão aí representadas; são três gerações que se acomodam na embarcação e contemplam passivas e expectantes aquele sobrevoo. $\mathrm{O}$ gesto de submissão à autoridade provedora reproduz-se, portanto, em escala socialmente ampliada, e a figura simbólica da águia é substituída pela do bombardeiro, que só pode saciar um tipo de fome: a de destruição. Os dois poemas colocam em cena o Estado, a um só tempo garantidor do alimento (na figura da águia) e de segurança contra um virtual inimigo (na figura do avião). O provimento é percebido pelos sujeitos que atravessam o lago com a mesma atitude de dependência e subordinação que caracteriza os que se sentam à mesa em Hábitos, ainda. Além disso, os dois meios de transporte figurados n' O céu deste verão, o de bombas e o de pessoas, caracterizam tempo e espaço distintos e virtualmente antagônicos. A pequena comunidade embarcada move-se à velocidade do remo. $\mathrm{O}$ braço armado do Estado eleva-se a "grande altitude" e viaja a centenas de quilômetros por hora. Ao erguerem os olhos para o alto, os que puxam os remos enxergam apenas um avião; por seu turno os tripulantes da aeronave contemplam um vasto panorama, que potencialmente engloba muitos barcos - vistos em seu conjunto, mas, evidentemente, não em seus detalhes. São perspectivas opostas, experiências vividas em dois mundos

\footnotetext{
${ }^{14}$ O céu deste verão [Der Himmel dieses Sommers]: „Hoch über dem See fliegt ein Bomber./ Von den Ruderbooten auf/ Schauen Kinder, Frauen, ein Greis. Von weitem/ Gleichen sie jungen Staren, die Schnäbel aufreißend/ Der Nahrung entgegen.“ (BRECHT 1993a: 313).
}

Pandaemonium, São Paulo, v. 24, n. 44, set.-dez. 2021, p. 351-373 
REDONDO, T. - As Elegias de Buckow, de Bertolt Brecht

diametralmente afastados um do outro, numa situação que guarda analogia com o que se passa n'A solução: a demanda por crescimento econômico acelerado, planejado pelos altos órgãos administrativos do governo, em conflito, embaixo, com a massa trabalhadora alijada do controle dos meios de produção necessários à execução do trabalho.

Após o levante de junho a Alemanha Ocidental foi acusada pela Oriental de ter interferido nos protestos por meio de agentes infiltrados na massa dos manifestantes. Sua missão teria sido a de incitar os trabalhadores que protestavam a assumir um discurso mais radical, com vistas não mais a uma pauta de reivindicações passível de negociação, mas à derrubada do governo e do regime. Independentemente do papel que os serviços de inteligência ocidentais possam ter desempenhado no conflito que se espalhou pelo país, vale repetir a insistência de Brecht na existência de um elemento autóctone de agitação. $\mathrm{Na}$ carta a Suhrkamp, ele aponta para a proveniência dos infiltrados: "jovens desclassificados" ao lado das "nítidas e brutais figuras dos tempos do nazismo, figuras locais que há anos não mais se apresentavam em grandes grupos e que, todavia, sempre estiveram aqui." Acresce que esses tipos, que ora emergiam das sombras, distinguiam-se dos trabalhadores revoltados, por seu método de ação: "Hoje, como então, não foram os trabalhadores que acenderam o fogo: ele não é a arma dos que constroem."

A imagem do fogo e da fumaça comparece em mais de uma das elegias de Buckow, mas seu significado varia consideravelmente de uma para outra. Jan Knopf vai notá-la também num poema em que ela não se revela explicitamente. Trata-se de Der Einarmige im Gehölz [O maneta no bosque $]^{15}$ :

\section{Empapado em suor, curva-se}

Para apanhar os gravetos secos. Afasta

Os mosquitos, abanando a cabeça. Com grande esforço

Amarra a lenha, que segura entre os joelhos. Levanta-se

Com um suspiro, ergue a mão, quer saber

Se chove. Mão erguida

O temido SS.

Um homem se esfalfa na simples tarefa de juntar gravetos. A condição de maneta indicada no título da elegia explica o esforço excessivo que o modesto trabalho demanda. Até aí, uma cena trivial, típica do ambiente campestre que se descortina em diversos

\footnotetext{
15 „DER EINARMIGE IM GEHÖLZ// Schweißtriefend bückt er sich/ Nach dem dürren Reisig. Die Stechmücken/ Verjagt er durch Kopfschütteln. Zwischen den Knien/ Bündelt er mühsam das Brennholz. Ächzend/ Richtet er sich auf, streckt die Hand hoch, zu spüren/ Ob es regnet. Die Hand hoch/ Der gefürchtete S. S. Mann.“(BRECHT 1993a: 312).
} 
REDONDO, T. - As Elegias de Buckow, de Bertolt Brecht

poemas das Elegias de Buckow. Finalizada a tarefa, porém, o gesto que a segue e a identificação do sujeito que a realiza ressignificam a cena completamente. Não é casual, aliás, a insistência do poema nesse gesto, o da mão erguida, que se apresenta no quinto e se repete no sexto verso. No sétimo e último, ao se saber a identidade de quem o protagoniza - o "temido SS" -, torna-se clara sua filiação ao ritual nazista de saudação ao Führer. Knopf diz que, dado o contexto histórico-político em que se inscrevem as elegias, ao enfeixar gravetos o ex-soldado só poderia estar preparando o combustível que iria arder nos protestos berlinenses em junho de 1953 (cf. KNOPF 1961: 14-15). O sujeito do poema seria, portanto, uma daquelas "nítidas e brutais figuras dos tempos do nazismo" mencionadas por Brecht na carta a Suhrkamp. Não obstante, a maneira como o SS é apresentado sugere ainda outra interpretação, que não elimina, mas complementa, a sugerida por Knopf. Os cinco versos iniciais evidenciam a fragilidade física do sujeito retratado, que está “empapado em suor” e não dispõe de uma mão livre para espantar os mosquitos que o atormentam. Dele, um "grande esforço" é cobrado pela tarefa de juntar gravetos, e o mero ato de se erguer acaba por lhe render um "suspiro". Assim, do ex-SS resta uma pálida lembrança de seu aterrorizante passado nazista, de pertença a um quadro de elite de suas forças repressivas, célebre pelas atrocidades cometidas contra mulheres e homens indefesos nas mais diversas frentes e particularmente nos campos de concentração e extermínio. Agora o "temido" carrasco não passa de um mutilado de guerra, incapaz de disparar um único tiro. $\mathrm{O}$ contraste entre a condição presente e o passado de fanático soldado hitlerista salienta a ironia da situação. É como se a voz lírica dissesse: "o outrora temido SS". A ação fascista perpetrada pelos que "todavia, sempre estiveram aqui" careceria de força real, a não ser que o fantasma de seu passado tomasse vulto em virtude de uma situação política favorável e voltasse a assombrar o presente. É pensando nessa hipótese que Brecht conclama o governo da RDA a abrir o diálogo com os trabalhadores. No início dos anos 1920, Hitler fora apenas o chefete de um grupelho de nacionalistas entre inúmeros outros que proliferaram nos tempos da República de Weimar. No fim da década, ele comandava não apenas um partido político hegemônico no campo da extrema-direita, mas também uma poderosa formação paramilitar, elemento essencial em sua luta pela tomada do poder. Sua real oportunidade política surgira no momento em que as lideranças dos partidos populares, com destaque para os dirigentes do Partido Social-Democrata, haviam se tornado reféns de sua política de conciliação com o capital, tornando-se alheios às necessidades das massas que se arruinavam no caos 
econômico. Para Hitler, chegara o momento azado: as massas trabalhadoras entregues à própria sorte, num quadro de crise econômica aguda e grande desorientação política. A elegia, como mostra Knopf, expressava o perigo representado pelo fascismo à espreita de mais uma oportunidade de agitação e ascenso em meio às massas populares, mas apontava, por outro lado, para sua fragilidade, ao menos enquanto a construção do socialismo não fosse apenas matéria do discurso oficial, mas um empreendimento realmente coletivo. Hoje, decorrido mais de meio século, vê-se que o poema adquire novo fôlego diante do crescimento do movimento neonazista na Alemanha, sobretudo no leste do país, justamente nos territórios que um dia integraram a RDA.

Para Brecht o risco de uma refascistização alemã não residia fundamentalmente na infiltração de agentes ocidentais, nem tampouco na atuação dos manetas que pudessem se organizar para promover incêndios. Ao largo do discurso oficial de construção de uma sociedade socialista, liberta das amarras do capital, reproduziam-se no país cenas de exploração do trabalho alheio que ele podia divisar até mesmo no idílico cotidiano de Buckow. Em Heisser Tag [Dia de calor] ${ }^{16}$ a reprodução de relações humanas que havia muito deveriam estar superadas captura subitamente o olhar que se distraíra com um quadro de beleza natural e idílica bonança:

Dia de calor. Sento-me no quiosque

Com o material de escrever no colo. Uma verde canoa

Se avista por entre as ramas dos chorões. Na popa

Uma freira gorda, vestindo roupas pesadas. Diante dela

Um homem velho em trajes de banho, um padre decerto.

À frente, remando com toda força

Uma criança. Como nos velhos tempos, penso

Como nos velhos tempos!

Em primeiro plano, o escritor e seu material de trabalho, o papel e a tinta. Não se sabe exatamente o que ele tem em mente ao se sentar - a continuação talvez de um texto? A mera contemplação da paisagem como forma de descontração antes de iniciar uma nova tarefa? O fato é que a canoa, em princípio mais um adereço da graciosa paisagem estival, transforma-se em fatídica mensageira da má notícia. Chega para relembrar o escritor da presença de uma velha adversária do socialismo. Na obra de Brecht a religião, aí representada pela freira e o sacerdote, comparece amiúde como entrave à ciência e

\footnotetext{
${ }^{16}$ „HEISSER TAG// Heißer Tag. Auf den Knien die Schreibmappe/ Sitze ich im Pavillon. Ein grüner Kahn/ Kommt durch die Weide in Sicht. Im Heck/ Eine dicke Nonne, dick gekleidet. Vor ihr/ Ein ältlicher Mensch im Schwimmanzug, wahrscheinlich ein Priester./ An der Ruderbank, aus vollen Kräften rudernd/ Ein Kind. Wie in alten Zeiten! Denke ich/ Wie in alten Zeiten!“ (BRECHT 1993a: 308).
}

Pandaemonium, São Paulo, v. 24, n. 44, set.-dez. 2021, p. 351-373 
REDONDO, T. - As Elegias de Buckow, de Bertolt Brecht

como tenaz adversária das forças sociais progressistas. Em Galileu, por exemplo, é protagonista de uma falácia anticientífica que ajuda a sustentar o regime feudal claudicante, e no poema $O$ Alfaiate de Ulm ela simplesmente desdenha da humanidade e seu velho sonho de voar. Sua sobrevida reside na manutenção do status quo ou, como sugere a elegia, na atuação regressiva, que inclui a exploração do trabalho infantil. $\mathrm{O}$ desconforto causado pela cena é de tal monta que o escritor se vê forçado a repetir o gesto que ele retratara uma vez em Schlechte Zeit für Lyrik [Tempos ruins para a poesia $]^{17}$, poema de 1939:

Sim, eu sei: apenas o sujeito feliz

É benquisto. Sua voz

É ouvida com prazer. Seu rosto é bonito.

A árvore recurvada no quintal

É sinal da terra empobrecida, mas

Os passantes tacham-na de raquítica

E têm toda razão.

Os barcos verdes e as alegres velas no canal

Eu não enxergo. De tudo

Vejo apenas a estropiada rede dos pescadores.

Por que fico o tempo todo a dizer

Que uma aldeã quarentona anda encurvada?

O peito das moças

Continua cálido como sempre.

Em minha canção uma rima

Se me afigura quase um gesto arrogante.

Em meu íntimo digladiam

$\mathrm{O}$ encanto provocado pela macieira em flor

E o horror suscitado pelos discursos do pintor de paredes ${ }^{18}$.

Mas apenas o segundo

Me obriga à escrivaninha.

Na elegia até mesmo a cor da canoa repete a dos barcos no canal da Dinamarca ${ }^{19}$, e nela se renova a disputa que opõe o desfrute da paisagem à necessidade de defrontar 0 elemento que estorva o cenário. Vê-se que os tempos permanecem ruins para a poesia,

\footnotetext{
17 „SCHLECHTE ZEIT FÜR LYRIK// Ich weiß doch: nur der Glückliche/ Ist beliebt. Seine Stimme/ Hört man gern. Sein Gesicht ist schön.// Der verkrüppelte Baum im Hof/ Zeigt auf den schlechten Boden, aber/ Die Vorübergehenden schimpfen ihn einen Krüppel/ Doch mit Recht.// Die grünen Boote und die lustigen Segel des Sundes/ Sehe ich nicht. Von allem/ Sehe ich nur der Fischer rissiges Garnnetz./ Warum rede ich nur davon/ daß die vierzigjährige Häuslerin gekrümmt geht? Die Brüste der Mädchen/ Sind warm wie ehedem.// In meinem Lied ein Reim/ Kämme mir fast vor wie Übermut.// In mir streiten sich/ Die Begeisterung über den blühenden Apfelbaum/ Und das Entsetzen über die Reden des Anstreichers. Aber nur das zweite/ Drängt mich zum Schreibtisch.“ (BRECHT 1993b: 432).

${ }^{18}$ Pintor de paredes [Anstreicher]: Alusão a Hitler, que na juventude acalentou, sem sucesso, o sonho de ser pintor, tendo fracassado em duas tentativas de ingressar na Academia de Artes de Viena.

${ }^{19}$ O poema foi escrito na Dinamarca, onde Brecht se exilara de 1933 a 1939.
} 
com o ovo da serpente sendo chocado à vista de todos. Não obstante, a despeito da denúncia de sua natureza retrógrada, convém ainda matizar a atitude de Brecht diante da religião. Durante a ditadura de Hitler, especialmente nos anos que antecederam a guerra, o poeta defendeu a ação política dos cristãos antifascistas, chamando a atenção da esquerda para o caráter progressista do cristianismo quando comparado ao paganismo nazista, segundo ele, uma forma muito mais regressiva e perniciosa de religião:

No Terceiro Reich, desenrola-se não uma luta contra a religião, mas uma luta entre duas religiões. O novo paganismo não é ateísmo, é antes, como o velho paganismo, uma religião. E, comparado ao cristianismo, uma religião atrasada. [...]

Nas lutas alemãs em torno da religião, nós, comunistas, devemos combater ao lado da religião mais avançada, da mesma maneira que, na nova guerra em que nos encontramos, devemos permanecer ao lado das democracias, das formas de Estado mais avançadas. Uma coisa não liquida nem interrompe nossa luta por uma visão de mundo materialista. A outra não liquida nem interrompe nossa luta por uma ordem social socialista (BRECHT 1993d: 588-89).

Não se pode, portanto, atribuir a Brecht o pecado da intolerância ou do sectarismo. Também a religião havia de ser considerada em perspectiva histórica. Na elegia, porém, ela volta a ocupar sua velha posição de força reacionária. O recreio de dois religiosos à custa de uma criança é a ilustração mais acabada de um arranjo social que tolerava ou abonava estruturas de dominação em tudo contrárias à expectativa de emancipação dos trabalhadores. O discurso governamental antifascista esvaziava-se diante do quadro que empanava o instante feliz e impelia mais uma vez o escritor à escrivaninha. Vale notar que a elegia revela um poeta precavido: no abrigo destinado à descontração, ele se senta já "com o material de escrever no colo". Trabalho e fruição aparecem, portanto, como dois momentos umbilicalmente ligados.

Para Brecht a lida artística e literária sujeitava-se como tudo o mais a alterações exigidas pelo próprio desenvolvimento da obra ou por demandas aparentemente externas a ela. Como disse certa vez, a "ideia do caminho correto não é tão boa quanto a de caminhar corretamente" (BRECHT 1993d: 569), de modo que, inversamente, um chamado qualquer, o da natureza, por exemplo, podia impor uma alteração na rota originalmente traçada e o abandono do gabinete de trabalho em favor de uma tarefa urgente no quintal de casa, como se dá em Der Schneesturm [A tempestade de neve] ${ }^{20}$, primeira parte de um ciclo intitulado Frühling 1938 [Primavera 1938]:

\footnotetext{
20 „DER SCHNEESTURM// Heute, Ostersonntag früh/ Ging ein plötzlicher Schneesturm über die Insel./ Zwischen den grünenden Hecken lag Schnee. Mein junger Sohn/ Holte mich zu einem Aprikosenbäumchen an der Hausmauer/ Weg von einer Schrift, wo ich auf jene mit dem Finger deute/ Welche einen Krieg
} 
REDONDO, T. - As Elegias de Buckow, de Bertolt Brecht

Hoje, Domingo de Páscoa, pela manhã

Uma súbita tempestade desabou sobre a ilha.

A neve restou entre as sebes enverdecidas. Meu filho pequeno

Levou-me a um miúdo damasqueiro junto ao muro da casa

Apartando-me de um texto em que aponto com o dedo para aqueles

Que preparam uma guerra destinada

A exterminar

O continente, esta ilha, meu povo, minha família e eu. Calados

Cobrimos com um saco

A árvore enregelada.

É preciso levar em conta essa via de mão dupla no trabalho cotidiano quando se considera a figura do poeta em Dia de calor. Sua presença, num cenário que não se reduz à descrição daquilo que ele contempla, implica substancial alteração do gesto de pesar e rememoração na chave já indicada. Lamenta-se, mais uma vez, não o evento passado, mas algo que dele retorna, e se inclui no quadro de lamentação a figura que lamenta. Desse modo, ambas as situações, a do observador e a dos observados, tornam-se síncronas, impondo-se um decisivo limite ao distanciamento temporal requerido para a rememoração, da mesma maneira que se abre espaço para um comentário, ainda que este se reduza a uma sucinta expressão de desalento: "como nos velhos tempos, penso, como nos velhos tempos!" Um passado que se queria morto e enterrado apresenta-se vivo e perfeitamente adaptado às novas condições. Desta feita, seu retorno não está circunscrito à presença de um grupo de fascistas conspirando num covil; ele é flagrado num evento inscrito na ordem cotidiana e observável à luz do dia.

Der Hund $[\mathrm{O} \text { cão] }]^{21}$, último poema das elegias de Buckow, reitera a observação de uma mentalidade avessa ao horizonte de liberdade e fraternidade que se deveria abrir em meio à construção da sociedade socialista. No poema já não se trata da voz empostada e autoritária de um alto funcionário ou dirigente do partido; é o homem do povo que expressa a contradição; é o interessado maior na transformação de relações sociais herdadas que insiste num estado de zelosa vigilância contra potenciais inimigos, ainda que estes se limitem à condição de pequenos meliantes interessados no furto de uma casa:

Diz-me o jardineiro: o cão

É forte e inteligente e foi comprado

Para guardar o jardim. O senhor, porém,

Educou-o para ser amigo das pessoas. Por que

Ganha ele sua ração?

vorbereiten, der/ Den Kontinent, diese Insel, mein Volk, meine Familie und mich/ Vertilgen muß. Schweigend/ Legten wir einen Sack/ Über den frierenden Baum.“ (BRECHT 1993a: 120).

${ }^{21}$ „DER HUND// Mein Gärtner sagt mir: Der Hund/ Ist kräftig und klug und gekauft/ Die Gärten zu bewachen. Sie aber/ Haben ihn erzogen zum Menschenfreund. Wofür/ Bekommt er sein Fressen?"“ (BRECHT 1993c: 270).

Pandaemonium, São Paulo, v. 24, n. 44, set.-dez. 2021, p. 351-373 
Como mercadoria o cão tem seu valor de uso profanado pelo dono, um sujeito desatento à finalidade da compra. Que a afeição do animal possa se estender a outras pessoas e se universalizar é ideia que escapa à Weltanschauung do jardineiro, subordinado a uma lida diária avessa ao luxo representado pela posse de um animal de estimação. Adquirido como meio destinado à produção de segurança, o cão que aprendeu a abanar o rabo só pode ser visto como capital desperdiçado. Ao opor os pontos de vista do jardineiro e do dono do cão, a elegia aponta para a situação da classe trabalhadora alemã numa perspectiva ainda distante daquela que Brecht quisera um dia vislumbrar num futuro socialista, sendo análoga àquela experimentada por ele e seus companheiros de luta nos tempos de enfrentamento da Alemanha hitlerista: a perspectiva da luta que endurece o coração, a qual leva os combatentes do fascismo ao limite de sua própria desumanização. $\mathrm{Na}$ admoestação do jardineiro ecoam ainda os versos da penúltima estrofe do conhecido poema An die Nachgeborenen [Aos pósteros], de 1939:

Contudo, sabemos:

Também o ódio à vilania

Transtorna os semblantes.

Também a ira contra a injustiça

Torna a voz roufenha. Ah, nós

Que queríamos preparar o caminho para a gentileza

Não pudemos nós mesmos ser gentis. ${ }^{22}$

Foi decerto com profunda consternação que Brecht escreveu $O$ cão. Que um trabalhador tivesse de se excluir dos prazeres proporcionados pelo convívio social ameno era uma questão que implicava uma realidade aquém das expectativas mais modestas em relação a uma sociedade de seres humanos livres e amparados por direitos igualmente compartilhados.

A elegia aponta ainda para uma questão particularmente sensível ao escritor: o mérito e a recompensa pelo trabalho, especialmente o artístico. Brecht, o artista que não se curvara às regras do realismo socialista ${ }^{23}$ nem à instrumentalização do teatro para fins de doutrinação, fazia na RDA as vezes de besta intelectual ${ }^{24}$, de animal irredutível às

\footnotetext{
${ }^{22}$ „Dabei wissen wir ja:/ Auch der Haß gegen die Niedrigkeit/ Verzerrt die Züge./ Auch der Zorn über das Unrecht/ Macht die Stimme heiser. Ach, wir/ Die wir den Boden bereiten wollten für Freundlichkeit/ Konnten selber nicht Freundlich sein.“ (BRECHT 1993a: 87).

${ }^{23} \mathrm{Em}$ meados dos anos 1930, Brecht recusara a crítica de Georg Lukács à literatura expressionista e as concepções do influente pensador e dirigente comunista em torno do realismo nas artes em geral e na literatura em particular. Na RDA do pós-guerra o chamado realismo socialista constituiu o cânone literário que Brecht confrontou até o fim da vida.

${ }^{24}$ Termo cunhado por Brecht num texto produzido por volta de 1937 para se referir aos intelectuais e artistas que lutavam contra o fascismo: "[..] sim, a inteligência é aquilo que não querem, aquilo que, com razão, não querem; a inteligência é o que devemos mobilizar contra eles. [...] Com efeito, esta é a questão principal:
} 
REDONDO, T. - As Elegias de Buckow, de Bertolt Brecht

tentativas de cooptação pelo regime. A recomendação de Girnus para que o governo entregasse a Brecht um teatro de grande porte foi atendida, mas não suas expectativas sobre o fracasso do "primitivo" e "puritano" encenador. De modo contrário à sua antecipada Schadenfreude, Brecht conquistaria não apenas o público alemão, ávido de alternativas às engessadas formas dramáticas oficialmente chanceladas, mas também a plateia e a crítica internacional a partir das excursões do Berliner Ensemble a Paris em 1954 e 1955. Brecht tornara-se definitivamente um cão avesso à domesticação, a um só tempo trunfo e pedra no sapato da alta direção política e partidária da RDA.

Durante o exilio americano, de 1941 a 1947, nem em seus piores sonhos Brecht teria podido imaginar que a vida espiritual na Alemanha do pós-guerra pudesse reproduzir a alienação e a subordinação de artistas e intelectuais a um poder sobre o qual eles não tivessem nenhum controle. Em Los Angeles ele havia deparado a colossal indústria hollywoodiana de entretenimento, que para promover seus efeitos narcotizantes sobre o público consumidor tinha antes de contar com a docilidade anestesiada de seus próprios agentes. Nas Elegias de Hollywood, trabalho realizado por volta de $1941 \mathrm{em}$ parceria com Hans Eisler, roteiristas, atores e atrizes, bem como os músicos de suas fábricas de sonho e os demais envolvidos na produção cinematográfica tiveram seu glamorizado trabalho rebaixado à condição do meretrício. Veja-se a quarta elegia ${ }^{25}$ :

Sob a copa das pimenteiras

Os músicos fazem seu trottoir, andando de par em par

Com os escrevinhadores. Bach

Tem um quarteto devasso no bolso. Dante remexe

$\mathrm{O}$ traseiro descarnado.

E também a elegia que a segue (não numerada):
A CIDADE FOI BATIZADA EM MEMÓRIA DOS ANJOS ${ }^{26}$
Que são encontrados por toda parte.
Recendem a óleo e usam pessários de ouro
E, com círculos azuis em torno dos olhos,
Durante toda a manhã alimentam os escrevinhadores em suas piscinas de lodo.

\begin{abstract}
como tornarmo-nos bestas intelectuais no sentido daquilo que é temido pelos fascistas em relação a seu poder? Uma besta é uma coisa forte, temível, dilaceradora. Isso soa bárbaro. Vamos, porém, acreditar que seja possível combater a barbárie mostrando-nos inofensivos?" (Gefährlichkeit der Intelligenzbestien. In: BRECHT 1993d: 341).

${ }^{25}$ „Unter den grünen Pfefferbäumen/ Gehen die Musiker auf den Strich, zwei und zwei/ Mit den Schreibern. Bach/ Hat ein Strichquartett im Täschchen. Dante schwenkt/ den dürren Hintern“ (BRECHT 1993a: 115).

26 „DIE STADT IST NACH DEN ENGELN GENNANT/ Und man begegnet allenthalben Engeln./ Sie riechen nach Öl und tragen goldene Pessare/ Und mit blauen Ringen um die Augen/ Füttern sie allmorgendlich die Schreiber in ihren Schwimpfühlen.“(BRECHT 1993a: 116).
\end{abstract}


REDONDO, T. - As Elegias de Buckow, de Bertolt Brecht

Na "buckólica” elegia As musas, Brecht emprega imagem análoga para tratar da submissão de intelectuais e artistas da RDA às diretrizes emanadas do aparato cultural oficial.
AS MUSAS ${ }^{27}$
Quando o homem de ferro as espanca
As musas cantam mais alto.
Com os olhos roxos
Adoram-no submissas.
O traseiro treme de dor
As vergonhas, de desejo.

É notável a similaridade que o poema guarda com a elegia de 1941. Lá os músicos e os escrevinhadores são gente que se prostitui, ainda que se apresentem como sendo a encarnação de Dante e Bach. Suas musas provêm de uma cidade que está coalhada delas: uma miríade de servas que os cercam em suas piscinas e que bem lembram a fila interminável das candidatas ao sonho do estrelato em Hollywood. Aqui, em 1953, as musas rodeiam uma única figura, a do amo que as escraviza. O círculo azul em torno dos olhos é substituído por uma maquiagem cuja produção prescinde do uso de tinturas e pincéis e é obtida por meio de socos e pontapés. A submissão é proporcional aos maustratos sofridos, a docilidade guarda correspondência direta com a dor infligida. O poema não foi publicado na pequena seleção de 1953. A figura do "homem de ferro" [Der Eiserne] aludia a Stalin (em alemão, der Stählerne, homem de aço), e os artistas e intelectuais que serviam ao aparato cultural do Estado tornavam-se eles mesmos as musas ou os anjos postos a circular em torno de seu mentor. Se não se obrigavam ao trottoir, uma vez que o Estado lhes provia a ocupação e o salário, estabeleciam uma relação de subalternidade ainda mais degradada que a de seus congêneres em Hollywood. Lá, os roteiristas, diretores e atores vendiam sua força de trabalho numa relação contratual com prazo fixo e, no limite, independente de afinidades ideológicas. Inúmeros atores, diretores e roteiristas hollywoodianos executavam a encomenda dos produtores, ainda que eventualmente assumissem posições políticas de contestação e procurassem encontrar no sistema brechas que lhes permitissem realizar um trabalho alternativo e contrahegemônico. Fosse como fosse, entregue a encomenda, estavam livres para negociar novamente seus préstimos no mercado de trabalho. N'As musas a relação de compra e venda do produto intelectual ou artístico se realiza de outro modo, não se tratando de mera

\footnotetext{
27 „DIE MUSEN// Wenn der Eiserne sie prügelt/ Singen die Musen lauter./ Aus gebläuten Augen/ Himmeln sie ihn hündisch an./ Der Hintern zuckt vor Schmerz/ Die Scham vor Begierde." (BRECHT 1993a: 313).
}

Pandaemonium, São Paulo, v. 24, n. 44, set.-dez. 2021, p. 351-373 
REDONDO, T. - As Elegias de Buckow, de Bertolt Brecht

adesão ou conversão ideológica. A cooptação se realiza por meio de um processo que chega ao terreno da economia libidinal. Os implicados enredam-se num jogo sadomasoquista que os torna potencialmente refratários a qualquer forma de reflexão e autonomia intelectual. Os Processos de Moscou já haviam indicado até onde se podia chegar na operação de acumpliciamento de corações e mentes, tendo apresentado ao mundo seu espetáculo de inconcebíveis confissões de traição e de crimes hediondos por parte de velhos revolucionários. Sofrimento e satisfação, renúncia e recompensa integravam a receita behaviorista aplicada no laboratório stalinista de controle social.

Somadas, as elegias aqui selecionadas compõem um mosaico de cenas flagradas no dia a dia da RDA recém-fundada, expondo elementos de uma relação social cujos traços mais sombrios remontavam aos tempos do fascismo histórico, além de apresentarem ecos da contraditória democracia americana em sua fase macartista. Sem embargo, é preciso ressaltar a grande complexidade do conjunto de poemas, que como dito de início, expressa uma opinião e um sentimento caracterizados pelo tom amargo e de quase resignação. Além das enormes dificuldades deparadas na organização do trabalho teatral, que obrigaram Brecht e Weil a uma aborrecida e tensa interlocução com a burocracia governamental, o escritor enfrentou no fim da vida problemas de saúde que paulatinamente se agravaram e impuseram um sério obstáculo à rotina diária de leituras e produção de textos, bem como aos ensaios do Berliner Ensemble. Por mais que se tenha insistido aqui no caráter de atualização dos temas tratados, é preciso também lembrar que seu viés melancólico (predominante talvez, mas não exclusivo) origina-se em boa medida de um olhar que, em alguma medida, é também retrospectivo, envolvido num ajuste de contas com o passado pessoal. Por outro lado, se para Brecht a reflexão e a produção artística foram sempre pautadas pela consciência de que a luta socialista, tanto no plano privado como no coletivo, havia de ser travada nos limites do momento histórico, era imprescindível investigar os materiais artísticos que estivessem efetivamente disponíveis e descobrir a melhor forma de utilizá-los, ainda que se afigurassem como rudimentares e pouco adequados à primeira vista. Seria o correto modo de uso o elemento que garantiria seu real aproveitamento. Entre as mais de vinte elegias de Buckow, restou uma única não intitulada, a mais breve de todas. Tom Kuhn e David Constantine empregaram-na como epígrafe para sua tradução das elegias. Fizeram-no com acerto, pois ela de algum modo sintetiza o ponto de vista mais geral que orienta a obra:

Pandaemonium, São Paulo, v. 24, n. 44, set.-dez. 2021, p. 351-373 
REDONDO, T. - As Elegias de Buckow, de Bertolt Brecht

Houvesse vento

Eu poderia içar uma vela.

Não a houvesse

Faria uma de lona e pedaços de pau. ${ }^{28}$

A elegia resume uma atitude combativa e, ao mesmo tempo, realista. A ocorrência do vento, condição primordial para que o barco se mova, convida o marinheiro ao mar. Navegante tarimbado, sabe ele que pode se lançar à viagem, ainda que tenha de improvisar o velame. Nada, em princípio, impede o cumprimento da tarefa. Todavia, o poema não dá margem a veleidades ou a qualquer espécie de voluntarismo. Nada se faz fora do tempo azado, do momento em que se reúnem as condições materiais necessárias ao empreendimento. O emprego do verbo no condicional - "Houvesse vento..." - indica a adoção dessa baliza. Faz parte do trabalho prévio à jornada o estudo e a observação atenta dos sinais que o céu e o mar estão a oferecer ao que deseja zarpar. Assim também, insistia Brecht, a luta socialista se subordinava à exaustiva investigação do instante propício para a ação revolucionária. Seja como for, a imagem do vento sugere também a ideia de que esse momento sempre acaba por chegar. Não há calmaria que sempre dure, como não há tempestade que jamais se encerre, e do mesmo modo, no momento certo, faz-se teatro e poesia com "lona e pedaços de pau", com os elementos de realidade que estejam à mão. E se a tarefa é produzir uma vela, melhor o tecido rústico do que a seda mais fina.

\section{Referências bibliográficas}

BRECHT, Bertolt. Große kommentierte Berliner und Frankfurter Ausgabe. Berlin: AufbauVerlag: Frankfurt am Main: Suhrkamp, 1993a. v. 12.

BRECHT, Bertolt. Große kommentierte Berliner und Frankfurter Ausgabe. Berlin: AufbauVerlag: Frankfurt am Main: Suhrkamp, 1993b. v. 14.

BRECHT, Bertolt. Große kommentierte Berliner und Frankfurter Ausgabe. Berlin: AufbauVerlag: Frankfurt am Main: Suhrkamp, 1993c. v. 15.

BRECHT, Bertolt. Große kommentierte Berliner und Frankfurter Ausgabe. Berlin: AufbauVerlag: Frankfurt am Main: Suhrkamp, 1993d. v. 22.1.

BRECHT, Bertolt. Große kommentierte Berliner und Frankfurter Ausgabe. Berlin: AufbauVerlag: Frankfurt am Main: Suhrkamp, 1995. v. 27.

BRECHT, Bertolt. Große kommentierte Berliner und Frankfurter Ausgabe. Berlin: AufbauVerlag: Frankfurt am Main: Suhrkamp, 1998. v. 30.

BRECHT, Bertolt. The Collected Poems. Edição e tradução: Tom Kuhn, David Constantine. New York: Liveright: London: W. W. Norton \& Company, 2019.

28 "Ginge da ein Wind/ Könnte ich ein Segel stellen./ Wäre da kein Segel/ Machte ich eines aus Stecken und Plane.” (BRECHT 1993a: 310).

Pandaemonium, São Paulo, v. 24, n. 44, set.-dez. 2021, p. 351-373 
REDONDO, T. - As Elegias de Buckow, de Bertolt Brecht

JÜNGER, Ernst. Der Arbeiter: Herrschaft und Gestalt. Stuttgart: Klett-Cotta, 2014.

KITTSTEIN, Ulrich. Das lyrische Werk Bertolt Brechts. Stuttgart: J.B. Metzler, 2012.

KNOPF, Jan. "Faschismus in der DDR. Zur Aktualität von Brechts Lyrik der Politik." In: https://sspace.snu.ac.kr/handle/10371/84498

KNOPF, Jan. Bertolt Brecht. Lebenskunst in finsteren Zeiten. Munique: Carl Hanser, 2012.

LöWY, Michel. Walter Benjamin: Aviso de incêndio. Uma leitura das teses"'Sobre o conceito de história”. São Paulo: Boitempo, 2005.

MenNemeIER, Franz Norbert. Bertolt Brechts Lyrik: Aspekte, Tendenzen. Düsseldorf: Bagel, 1982.

SCHUHMANN, Klaus. Untersuchungen zur Lyrik Brechts. Berlin: Aufbau, 1977.

Recebido em 25 de agosto de 2020

Aceito em 29 de novembro de 2020

Pandaemonium, São Paulo, v. 24, n. 44, set.-dez. 2021, p. 351-373 